Published in final edited form as:

Am J Obstet Gynecol. 2016 October ; 215(4): 406-407. doi:10.1016/j.ajog.2016.06.060.

\title{
Pregnancy as a window to future health: short term costs and consequences
}

\author{
Janet M. CATOV, PhD, MS ${ }^{1,2}$ and Claire MARGERISON-ZILKO ${ }^{3}$ \\ ${ }^{1}$ Department of Obstetrics, Gynecology and Reproductive Sciences \& Epidemiology, University of \\ Pittsburgh School of Medicine, Pittsburgh, PA \\ ${ }^{2}$ Magee-Womens Research Institute, Pittsburgh, PA \\ ${ }^{3}$ Department of Epidemiology and Biostatistics, Michigan State University, East Lansing, MI
}

Cardiovascular disease (CVD) is the leading killer of women. ${ }^{1}$ Mortality among younger women is increasing at an alarming rate, and profound race disparities persist. ${ }^{2}$ Early detection is essential, and yet traditional cardiovascular screening paradigms fall short in women as their risk presents differently than men. Women with pregnancies complicated by preeclampsia, preterm or small-for-gestational age (SGA) births have excess hypertension and cardiometabolic risk after delivery compared to women with uncomplicated pregnancies. ${ }^{3}$ Long-term costs associated with CVD across the life course are staggering and expected to increase. ${ }^{4}$ The report by Cain, et al, now reveals that short-term costs of CVD in women with pregnancy complications exceed $\$ 63$ million within five years of delivery. ${ }^{5}$

There is much we do not yet know about the emergence of CVD in women during the reproductive years. Cain and co-authors make an important contribution by demonstrating that the burden of this risk is detectable — and costly—within five years of delivery. Their results likely reflect only the tip of this excess risk. For example, early detection of hypertension is critical, as treatment is widely available, inexpensive and cardio-protective. Yet, $32-38 \%$ of hypertension goes undetected before age $40 .{ }^{6}$ Hypertension contributes to more CVD events in women relative to men (32\% vs. $19 \%) .{ }^{7}$ Related, the accumulation of modest blood pressure elevations over young adulthood is linked to coronary calcification. ${ }^{8,9}$ Thus, the costs evaluated by Cain, et al, are likely an underestimate of the true burden of occult CVD risk that accumulates in women during the reproductive years.

The dataset deployed in this study is unique, as surveillance data in the United States that link births to maternal morbidity are lacking. Indeed, the foundational evidence that linked pregnancy history to maternal CVD mortality and morbidity came from large registries of linked data across the life course from European cohorts. ${ }^{10,11}$ The authors here linked more than 800,000 births in Florida to inpatient, outpatient and emergency department medical records five years before (to identify pre-existing disease) and five years after delivery. Importantly, they limited the population to nulliparous women to characterize the first

Corresponding Author: Janet M. Catov, PhD, MS, University of Pittsburgh, Department of Obstetrics, Gynecology and Reproductive Sciences, 300 Halket Street, Pittsburgh, PA 15213, Telephone (412) 641-6217, Facsimile (412) 641-1133, catovjm@ upmc.edu. 
pregnancy association with emerging cardiovascular events and studied incident CVD in more than 300,000 by excluding women with evidence of disease before pregnancy. Of note, they report that $13.8 \%$ of first births in Florida have a placental syndrome (preecalmapsia, placental infarct or abruption) and the prevalence of preterm birth and small for gestational age infants among this group is high.

This study also highlights much that we do not yet understand about the relationship between pregnancy complications and later-life cardiovascular health. They authors identified maternal and fetal syndromes, and yet our ability to discern the complex interplay between the two at the population level is limited. Maternal factors may impair placentation, and fetal response to these impairments likely triggers risk for offspring. The cross talk between fetus and mother, moreover, is known to be dynamic, complex and bi-directional and thus disentangling them may be almost impossible. In addition, we do not know if placental syndromes unmask maternal pre-existing vascular impairments or instigate lasting injury. Regardless, the health of mother and fetus are intimately linked and 'the great obstetrical syndromes' are now understood to mark long-term health consequences for both. As Cain, et al, have reported, this burden is detectable and costly within five years.

We also lack important knowledge regarding whether the relationship between pregnancy complications and later-life cardiovascular health differs by race, ethnicity, or socioeconomic status. Notably, non-Hispanic black women in the U.S. are $60 \%$ more likely to have a pregnancy complicated by preterm delivery compared to non-Hispanic white women, ${ }^{12}$ later in life, black women are at a $40 \%$ increased risk of CVD and have $50 \%$ higher rates of hypertension, compared to white women. ${ }^{2}$ Similar disparities in both pregnancy complications and cardiovascular health exist between women of high and low socioeconomic status (SES). Thus, a critical area for future research lies in determining whether the race and socioeconomic disparities in pregnancy health predict, unveil, or impact disparities in cardiovascular health later in life.

Pregnancy, a key point in which women interact with the medical system, provides a unique opportunity to identify women at risk of short- or long-term CVD. Pregnancy may also be a particularly relevant opportunity for prevention or intervention among minority or disadvantaged women who face barriers to accessing medical care. ${ }^{13}$ Recent interventions focused on preventing later-life diabetes among women with gestational diabetes have proven successful at reducing diabetes risk factors such as post-partum weight retention through relatively simple lifestyle interventions delivered via web and mail/telephone. ${ }^{14,15}$ Such work provides a possible template for similar low-cost interventions aimed at improving short term and long term cardiovascular health among women with placental syndromes.

\section{References}

1. Xu J, Murphy S, Kochanek K, Bastian B. Deaths: Final data for 2013. National Vital Statistics Reports. 2016; 64

2. Mosca L, Benjamin EJ, Berra K, et al. Effectiveness-based guidelines for the prevention of cardiovascular disease in women - 2011 update: a guideline from the American Heart Association. Journal of the American College of Cardiology. 2011; 57:1404-23. [PubMed: 21388771] 
3. Rich-Edwards JW, Fraser A, Lawlor DA, Catov JM. Pregnancy characteristics and women's future cardiovascular health: an underused opportunity to improve women's health? Epidemiologic reviews. 2014; 36:57-70. [PubMed: 24025350]

4. Heidenreich PA, Trogdon JG, Khavjou OA, et al. Forecasting the Future of Cardiovascular Disease in the United States: A Policy Statement From the American Heart Association. Circulation. 2011; 123:933-44. [PubMed: 21262990]

5. Cain M, Salemi J, Tanner J, Kirby RS, Salihu H, Louis J. Pregnancy as a window to future health: maternal placental syndromes and short-term cardiovascular outcomes. Am J Obstet Gynecol. 2016 Epub ahead of print.

6. Johnson HM, Thorpe CT, Bartels CM, et al. Undiagnosed hypertension among young adults with regular primary care use. Journal of Hypertension. 2014; 32:65-74. [PubMed: 24126711]

7. Cheng S, Claggett B, Correia AW, et al. Temporal Trends in the Population Attributable Risk for Cardiovascular Disease: The Atherosclerosis Risk in Communities Study. Circulation. 2014; 130:820-8. [PubMed: 25210095]

8. Pletcher MJ, Bibbins-Domingo K, Lewis CE, et al. Prehypertension during Young Adulthood and Coronary Calcium Later in Life. Annals of Internal Medicine. 2008; 149:91-9. [PubMed: 18626048]

9. Allen N, Berry JD, Ning H, Van Horn L, Dyer A, Lloyd-Jones DM. Impact of Blood Pressure and Blood Pressure Change During Middle Age on the Remaining Lifetime Risk for Cardiovascular Disease: The Cardiovascular Lifetime Risk Pooling Project. Circulation. 2012; 125:37-44. [PubMed: 22184621]

10. Irgens H, Reisaeter L, Irgens L, Lie R. Long term mortality of mothers and fathers after preeclampsia. BMJ. 2001; 323:1213-17. [PubMed: 11719411]

11. Smith G, Pell J, Walsh D. Pregnancy complications and maternal risk of ischaemic heart disease: a retrospective cohort study of 129,290 births. Lancet. 2001; 357:2002-6. [PubMed: 11438131]

12. Martin JA, Hamilton BE, Osterman MJ, Curtin SC, Matthews TJ. Births: final data for 2013. National vital statistics reports: from the Centers for Disease Control and Prevention. National Center for Health Statistics, National Vital Statistics System. 2015; 64:1-65.

13. Adler NE, Newman K. Socioeconomic disparities in health: pathways and policies. Health affairs (Project Hope). 2002; 21:60-76. [PubMed: 11900187]

14. Nicklas JM, Zera CA, England LJ, et al. A web-based lifestyle intervention for women with recent gestational diabetes mellitus: a randomized controlled trial. Obstet Gynecol. 2014; 124:563-70. [PubMed: 25162257]

15. Ferrara A, Hedderson MM, Brown SD, et al. The Comparative Effectiveness of Diabetes Prevention Strategies to Reduce Postpartum Weight Retention in Women With Gestational Diabetes Mellitus: The Gestational Diabetes' Effects on Moms (GEM) Cluster Randomized Controlled Trial. Diabetes Care. 2016; 39:65-74. [PubMed: 26657945] 